\title{
Prevalence of depression among elderly people living in old age home in the capital city Kathmandu
}

\author{
S Ranjan ${ }^{1}$, A Bhattarai $^{2}$, M Dutta $^{2}$ \\ ${ }^{1}$ Department of Psychiatry, Universal College of Medical Sciences, Bhairahawa, Nepal \\ ${ }^{2}$ Department of Nursing, National Medical College, Nursing Campus, Birgunj, Nepal
}

\begin{abstract}
Background: There has been a considerable increase in the numbers of older people in the world population of both developed and developing countries. These populations are thought to be at greater risk for depression. Many researches are conducted on physical wellbeing of elderly but studies regarding depression among elderly, especially in old age home is lesser in the developing countries. Objectives: To assess depression among elderly residing in an old age home in Kathmandu and its association with some of the socio-demographic variables. Methods: One hundred fifty elderly people residing in social welfare centre elderly home, Pashupatinath, Gaushala, Kathmandu, Nepal were selected randomly. Geriatric depression scale (GDS) was applied in all the individuals to assess the prevalence and degree of depression. Results: This study showed that, $47.33 \%$ of population had depression. Among the depressed population, $70.42 \%$ had mild depression and $29.58 \%$ had severe depression. There was significant association between the prevalence of depression and history of physical illness. Conclusion: Depressive disorder is highly prevalent among the elderly population residing in the old age home in Kathmandu with history of physical illness.
\end{abstract}

Keywords: depression, elderly, old age home, Kathmandu

\section{Introduction}

Ageing is a normal process, which is associated with physical, social and psychological changes. The number of older population of both developed and developing countries has considerably increased in the $20^{\text {th }}$ century. ${ }^{1}$ According to the 2001 census of Nepal, its elderly population constituted 6.5 percent of the total population of the country. During the years 1991-2001, the annual elderly population growth rate was 3.39 percent as against the national population growth rate of $2.3 \%$. According to the 2011 census, the percentage of elderly population has increased to 9.1 percent. The number of senior will increase because $54.7 \%$ of the total population is within the age group of $15-59$, which is reproductive. ${ }^{2}$

As the age advances there is increased morbidity and functional loss. Also presence of varying life events,

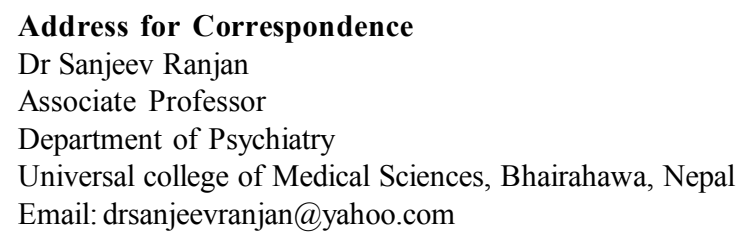

greatly impact on one's psychological status, making them more prone to depression. ${ }^{3}$ Thirty four studies have reported prevalence of depression in the community-dwelling elderly with widely varying findings (0.4-35\%). Furthermore, most of these studies were performed in developed countries. ${ }^{4}$

Depression among elderly has also been found to be associated with some socio-demographic variables like age, gender, educational status, marital status, psychological support, presence of chronic illness, length of stay in the old age homes etc.

So this study was undertaken to assess the prevalence of depression among elderly staying in old age home in Nepal and its association with some of the sociodemographic variables.

\section{Methods}

This study was a cross sectional institute-based study conducted at "Social Welfare Centre Elderly's Home, Pashupatinath" at Gaushala, Kathmandu. It is the only Elderly's Home operated by Government of Nepal. It 
was established in 1882 A.D in the regime of king Surendra Shah and operated as being the Panchadeval Pakshala. It is being operated by the name of Social Welfare Centre Elderly's Home, Pashupati since 1977 A. D. The total sheltering capacity of this Elderly Home is 230 persons. To get shelter here, the elderly should have a Nepalese citizenship certificate of completion of 65 years of age, a recommendation letter from the concerned Village Development Committee or Municipality, stating that the person is orphan, helpless, poor and he has no body to take care of.

This elderly home provides maintenance and housing, health care and sanitation, clothing, celebration of traditional festivals, pilgrimage, religious programmes and funeral rites to the elderly residing here.

Regarding health care, there is provision of posting an ANM by health ministry for daily medical care and invigilence of health status and recommendation. Personally some doctors visit the organization on volunteer basis. With the collaboration of the ANM and these health personnel the elderly are treated and are referred to suitable health centre as per the need. No special check up regarding psychiatric illness has been done.

This centre is funded by the Ministry of Women, children and social welfare of Nepal and donation received from different individuals on their personal basis.

One hundred and fifty elderly people (65 years and above) fulfilling the inclusion criteria mentioned below were selected consecutively.

Inclusion criteria: Elderly people of $65 \mathrm{yrs}$ and above.

Exclusion criteria: The elderly people who were unable to speak, hear, complete the interview process, did not consent to participate in this study and those who did not understand Nepali language was excluded from the study.

A list of 12 items, self-designed questionnaire was used to collect information about socio-demographic variables which included age, sex, address, education, religion, marital status, past occupation, reason for admission in old age home, history of any physical illness, duration of stay at the institute, psychological and financial support.

Modified Geriatric Depression Scale (GDS) was administered to assess the prevalence and degree of depression among the subjects. GDS is an internationally validated questionnaire showing a sensitivity of $85 \%$ and specificity of $74 \%{ }^{5}$ This scale has also been found to be reliable and valid in Nepal. ${ }^{5,6}$ This scale, originally in English language, was first translated in Nepali medium by and English to Nepali translator and again the translated version was given to independent expert for English translation to minimize inconsistency. The final Nepali medium questionnaire of the GDS was used.

Geriatric Depression Scale is a 30 item questionnaire especially developed as a screening instrument of depressive symptom in elderly. The GDS questions are answered "yes" or "no". This simplicity enables the scale to be used with ill or moderately cognitively impaired individuals. One point is assigned to each answer and the cumulative score is rated on a scoring grid. The grid sets a range of 0-9 as "normal", 10-19 as "mildly depressed", and 20-30 as "severely depressed".

"Psychological support" was taken as any visits or communication with relatives, friend or any unknown person. $^{7}$

"Financial support" was taken as a relative, friend or unknown person giving money to the individual. ${ }^{7}$

Regarding medical morbidities, those elderly who were on regular medications prescribed by doctor were included. The medical illness was further confirmed by taking detail medical history

Ethical consideration: Ethical approval was obtained from the concerned authority of the college. Verbal informed consent was obtained from the participants. Purpose of data collection was explained to the respondents before interviewing. Privacy and confidentiality of all respondents was maintained.

Descriptive statistics and inferential statistics were used to analyze the data. Under descriptive statistics percentage was calculated and using the inferential statistics, chi square test was done to find the association between the prevalence of depression with the selected demographic variables.

\section{Results}

Regarding socio-demographic variables, $18.31 \%$ of the respondents were in the age group of 65-69 years, $33.80 \%$ were of the age group $70-74$ years, $32.40 \%$ were of the age group of $75-79$ years, $15.49 \%$ were 80 years and above. 
Male constituted $43.66 \%$ of total population while $56.34 \%$ of total population was female.

All the respondents followed Hindu religion. Out of total population, $53.33 \%$ were from rural area, $30 \%$ were from urban area and $16.66 \%$ from semi urban area. Majority of them (78\%) were uneducated. Regarding marital status, $52 \%$ were widow/widower, $26.66 \%$ were separated, $15.33 \%$ were single, $5.33 \%$ were married and $0.006 \%$ was divorced.

Majority of them (54.67\%) got psychological support where as $45.33 \%$ of total population had not got any psychological support from either family member or friends. Higher part (58.67\%) of the respondents had got financial support whereas $41.33 \%$ had not. The subjects were admitted in the old age home in lack of caregiver (64\%), $10.67 \%$ because of family conflict, $9.33 \%$ because of loss of spouse, $6 \%$ due to low economy and $1 \%$ on their own will.

In this social welfare centre elderly home, $3.33 \%$ of the respondents were staying for less than 1 month, $5.33 \%$ for less than 6 month, $8 \%$ for less than 1 year and $83.33 \%$ for more than 1 year.

Out of 150 respondents seventy one $(47.33 \%)$ had depression (Table 1).

Table 1: Distribution of respondents according to prevalence of depression and its degree

\begin{tabular}{|l|l|l|l|l|l|l|}
\hline & \multicolumn{3}{|l|}{ Prevalence of depression (N=150) } & \multicolumn{3}{l|}{ Degree of depression (N=71) } \\
\hline & Normal & Depression & Total & Mild & Sever & Total \\
\hline Frequency & 79 & 71 & 150 & 50 & 21 & 71 \\
\hline Percent & $52.67 \%$ & $47.33 \%$ & $100 \%$ & $70.42 \%$ & $29.58 \%$ & $100 \%$ \\
\hline
\end{tabular}

Among the depressed population, fifty $(70.42 \%)$ were having mild depression and twenty one (29.58\%) had severe depression (Table 1). Sixty four percent of the population had history of chronic physical illness like gastrointestinal $(25.33 \%)$, respiratory $(16.66 \%)$, neurological (6\%), musculoskeletal (13.33\%), cardiovascular $(6 \%)$, sensory $(10.67 \%)$, endocrinal $(3.32 \%)$ and others. Depression was found to be significantly associated with physical illness. There was no significant association found between the other socio demographic variables (Table 2).

Table 2: Association between depression and socio-demographic variables

\begin{tabular}{|c|c|c|c|c|c|c|c|}
\hline $\begin{array}{l}\text { Socio } \\
\text { demographic } \\
\text { variables }\end{array}$ & \begin{tabular}{|l} 
Mild \\
depression
\end{tabular} & \begin{tabular}{|l|} 
Severe \\
depression
\end{tabular} & Total & Chi-square & $P$ value & \begin{tabular}{|l} 
Tabulated \\
value
\end{tabular} & Remarks \\
\hline Age in years & & & & \multirow[t]{5}{*}{5.48} & \multirow[t]{5}{*}{0.05} & \multirow[t]{5}{*}{7.825} & \multirow{5}{*}{$\begin{array}{c}\text { non-significant } \\
-\end{array}$} \\
\hline $65-69$ & 8 & 5 & 13 & & & & \\
\hline $70-74$ & 21 & 3 & 24 & & & & \\
\hline $75-79$ & 15 & 8 & 23 & & & & \\
\hline$>80$ & 6 & 5 & 11 & & & & \\
\hline Gender & & & & \multirow[t]{3}{*}{1.298} & \multirow[t]{3}{*}{0.05} & \multirow[t]{3}{*}{3.841} & \multirow[t]{3}{*}{ non-significant } \\
\hline Male & 24 & 7 & 31 & & & & \\
\hline Female & 26 & 14 & 40 & & & & \\
\hline $\begin{array}{l}\text { Educational } \\
\text { status }\end{array}$ & & & & \multirow[t]{3}{*}{1.5731} & \multirow[t]{3}{*}{0.05} & \multirow[t]{3}{*}{3.841} & \multirow[t]{3}{*}{ non-significant } \\
\hline Educated & 6 & 5 & 11 & & & & \\
\hline Uneducated & 44 & 16 & 60 & & & & \\
\hline Marital status & & & & \multirow[t]{6}{*}{1.21} & \multirow[t]{6}{*}{0.05} & \multirow[t]{6}{*}{9.488} & \multirow[t]{6}{*}{ non-significant } \\
\hline Widow & 26 & 11 & 37 & & & & \\
\hline Separated & 15 & 7 & 22 & & & & \\
\hline Married & 3 & 2 & 5 & & & & \\
\hline Single & 5 & 1 & 6 & & & & \\
\hline Divorced & 1 & 0 & 1 & & & & \\
\hline
\end{tabular}




\begin{tabular}{|c|c|c|c|c|c|c|c|}
\hline $\begin{array}{l}\text { Psychological } \\
\text { support }\end{array}$ & & & & \multirow[t]{3}{*}{1.69} & \multirow[t]{3}{*}{0.05} & \multirow[t]{3}{*}{3.841} & \multirow[t]{3}{*}{ non-significant } \\
\hline Yes & 20 & 5 & 25 & & & & \\
\hline No & 30 & 16 & 46 & & & & \\
\hline $\begin{array}{l}\text { Financial } \\
\text { support }\end{array}$ & & & & \multirow[t]{3}{*}{0.0119} & \multirow[t]{3}{*}{0.05} & \multirow[t]{3}{*}{3.841} & \multirow[t]{3}{*}{ non-significan } \\
\hline Yes & 16 & 7 & 23 & & & & \\
\hline No & 34 & 14 & 48 & & & & \\
\hline $\begin{array}{l}\text { Reason for } \\
\text { leaving home }\end{array}$ & & & & \multirow[t]{6}{*}{7.999} & \multirow[t]{6}{*}{0.05} & \multirow[t]{6}{*}{9.488} & \multirow[t]{6}{*}{ non-significant } \\
\hline Loss of spouse & 6 & 2 & 8 & & & & \\
\hline Low economy & 4 & 1 & 5 & & & & \\
\hline Family conflict & 4 & 7 & 11 & & & & \\
\hline Lack of caretaker & 35 & 10 & 45 & & & & \\
\hline Self & 1 & 1 & 2 & & & & \\
\hline Length of stay & & & & \multirow{5}{*}{6.502} & \multirow[t]{5}{*}{0.05} & \multirow[t]{5}{*}{7.815} & \multirow{5}{*}{ non-significant } \\
\hline$<1$ month & 3 & 0 & 3 & & & & \\
\hline$<6$ month & 0 & 2 & 2 & & & & \\
\hline$<1$ year & 5 & 1 & 6 & & & & \\
\hline$>1$ year & 42 & 18 & 60 & & & & \\
\hline $\begin{array}{l}\text { History of } \\
\text { physical illness }\end{array}$ & & & & \multirow[t]{3}{*}{5.1218} & \multirow[t]{3}{*}{0.05} & \multirow[t]{3}{*}{3.841} & \multirow[t]{3}{*}{ significant } \\
\hline Yes & 32 & 19 & 51 & & & & \\
\hline No & 18 & 2 & 20 & & & & \\
\hline
\end{tabular}

\section{Discussion}

In our study, depression was found to be highly prevalent among elderly $(47.33 \%)$. This finding of our study is supported with similar studies conducted on the study of depression among geriatric population in Nepal, which showed that $53.2 \%$ of the samples experience depressive illness according to GDS. ${ }^{5}$ Similarly another study from a tertiary level hospital in Nepal conducted among hospitalized geriatric medical inpatients concluded that $57.1 \%$ of hospitalized geriatric patient had depressive symptoms and $17.3 \%$ of healthy community dwelling had depression. ${ }^{8}$ A study conducted on prevalence of depression among institutionalized elders in Colombo showed $56 \%$ of population had depression. ${ }^{7}$ Study conducted on community dwelling areas of West Bengal showed $53.7 \%$ depression. ${ }^{9}$ Cross-sectional descriptive survey done at elderly welfare centre and public health centers in Korea showed the prevalence of depression to be $63 \%{ }^{10}$

In contrast to above studies, there are studies which showed prevalence of depression among elderly to be lower than the above figures. The overall prevalence of depressive disorder among the elderly population of rural areas of Udupi district, Karnataka, India was found to be $21.7 \% .^{11}$ This difference in the prevalence with this study might be due to the different instruments used for measuring depression. But other studies which used the same instrument as our study to detect depression, also showed lower figure. The prevalence of depressive symptoms among community-dwelling elderly Sri Lankans was $27.8 \% .{ }^{12}$ A study done on the prevalence of depression among elderly in an urban area of Selangor, Malaysia found that prevalence of depression among elderly was $6.3 \%{ }^{1}$

Using the key score and leveling the margins for mild and severe depression, the study showed that among the depressed population, $70.42 \%$ had mild depression while $29.58 \%$ had severe depression. This result is in accordance with other studies which also showed that higher percentage of elder population suffered from mild depression than severe using GDS. ${ }^{5,7}$

Relating the socio-demographic variable and prevalence of depression, in this study it was found that there was significant association between the prevalence of depression and history of physical illness. This result is supported by the study done in Taiwan, which found out that there was high risk of depressive disorders among those with physical illness. ${ }^{13}$ Similarly, study conducted in Srilanka found that there was significant correlation of depressive symptoms with physical disability. ${ }^{12}$ Other studies too showed significant 
association between chronic illness and depression in elderly. ${ }^{1,7}$ But the study done in Korea showed a significantly low correlation of depression with comorbidity. ${ }^{10}$

In our study no significant association was found with other socio-demographic variables like age, gender, educational level, marital status, psychological support, financial support and length of stay in old age home. Another study also shows depression to have significantly low correlation with sex and education. ${ }^{10}$ In some studies depression was not found to be significantly associated with marital status s,, $14^{2}$ and gender. ${ }^{3,7}$ Similarly another study also found depression not to be significantly associated with age, financial support, employment status and literacy level. But other studies show depression in elderly to be significantly associated with gender, ${ }^{1,9,12}$ low financial support ${ }^{9,12}$ illeterate ${ }^{3,9}$ and marital status ${ }^{3}$.

Out of total respondents, $56.34 \%$ were female, $53.33 \%$ were from rural area and 30\% from urban area. All respondents followed Hindu religion (100\%). This is in accordance with our national population data which shows that majority ( $81.3 \%$ ) of the national population are Hindu, lesser population (17\%) resides in urban area and there are 796,422 more female than male in Nepal. ${ }^{15}$

In our study, the most common reason for admission in old age home was lack of care giver $(64 \%)$. It was similar to the one reported by study from Colombo. ${ }^{7}$

\section{Conclusion}

Depression is prevalent among elderly population residing in old age home in Kathmandu. They are more likely to suffer from mild than severe depression. Physical illness is significantly associated with the depression in elderly. Most of them move to old age home due to lack of care giver.

\section{Recommendations}

- A comparative study can be carried out to find out the prevalence of depression among elderly in old age home and community dwelling areas.

- Similar study can be undertaken with a large sample in other old age home to generalize the findings.

- A similar study can be done to develop the health education packages on prevention of elderly depression.
- Along with routine medical check-up, regular visit by psychiatrists should be done in elderly homes to detect and treat elderly suffering from depression and other psychiatric illness.

\section{Acknowledgements}

We are thankful to "Social Welfare Centre Elderly's Home, Pashupatinath" for allowing us to conduct this study.

\section{References}

1. Sherina, M., Sidik, R., Aini, M., \& Norhidayati, $\mathrm{H}$. The prevalence of depression among elderly in an urban area of Selangor, Malaysia. The International Med J. 2005; 4(2): 57-63.

2. Bhattarai, N. Nepal's ageing population: Are we prepared for elderly care? Retrieved on May 06, 2012. Available from: http:// www.nepalnews.com/home/index.php/guestcolumn/18567-nepals-ageing-population-are-weprepared-for-elderly-care.html.

3. Jariwala, V., Bansal, R.K., Patel, S., \& Tamakuwala, B. A study of depression among aged in Surat city. National J of comm Med. 2010; 1(1): 47-49.

4. Wada, T. Depression of community-dwelling elderly in three Asian countries: Myanmar, Indonesia and Japan. Archives of Gerontology. 2009; 20(18): $1-11$.

5. Khatri, J.B., \& Nepal, M.K. Study of depression among geriatric population in Nepal. Nepal Med Coll J. 2006; 8(4): 220-3.

6. Gautam, R., Houde, S. (2011). Geriatric Depression Scale for community-

dwelling older adults in Nepal. Asian J Gerontology Geriatr, 6: 93-9

7. Wijeratne, MDM, Wijerthne, SA, Wijesekara, SG, \& Wijesingha, I. Prevalence of depression among institutionalized elders in Colombo district. Student Med J. 2008; 1(1): 27-31.

8. Kumar, A., Sharma, R., Timalsina, S., Giri, S., \& Yadav, V. High prevalence of depression and anxiety symptoms among hospitalized geriatric medical inpatients: A study from a tertiary level hospital in Nepal. UTMJ. 2010; 88 (1): 34.

9. Maulik, S., \& Dasgupta, A. Depression and its determinants in the rural elderly of West Bengal-a 
cross sectional study. International J of Biomedical and Medical Research. 2012; 3(1): 1299-1302.

10. Kim, J.,Choe, M., \& Chae Y. Prevalence and predictor of geriatric depression in communitydweling elderly. Asian Nursing Research.2009; 3(3): 121-129.

11. Barua, A., \& Kar, N. (2010). Screening for depression in elderly Indian population. Indian J Psychiatry. 2010; 52(2): 150-153.

12. Malhotra, R., Chan, A., \& Õstbye, J. Prevalence and correlates of clinically significant depressive symptoms among elderly people in Srilanka :
Finding from a national survey. Int Psychogeriatrics. 2010; 22(2): 227-236.

13. Chong, M., Chen, C., Tsang, H., Yeh, T., Lee, Y., Tang, T., \& Lo, H. Community study of depression in old age. Br J Psychiatry. 2001; 178: 29-35.

14. Shrestha, L.S., and Pienta, M.A. "Validating the Centre for Epidemiological Studies Depression Scale (CES-D) for Use among Older Adults in Nepal". P 5-6. 15.

15. National Population and Housing census 2011 (National report). Government of Nepal, National Planning Commission Secretariat, Central Bureau of Statistics, Kathmandu, Nepal, 2012. 